
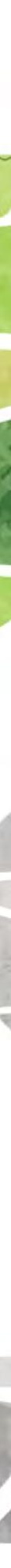

B. Téc. Senac, Rio de Janeiro, v. 43, n. 3, p. 86-103, set./dez. 2017. 
*Engenheiro Florestal. Aluno de Prática Profissionalizante na Escola Superior de Agricultura "Luiz de Queiroz" (Esalq) - Universidade de São Paulo (USP). Piracicaba, São Paulo, Brasil.

E-mail: rodrigo.fujiwara@ usp.br

** Doutora em Química e Doutora em Educação Escolar. Docente MS3 na Esalq - USP. Piracicaba, São Paulo, Brasil. E-mail: rosebelly.esalq@usp.br

Recebido para publicação em: 23.11.2016

Aprovado em: 31.7.2017

\section{O POTENCIAL FORMATIVO DO JOGO NO ENSINO DE ENGENHARIA AGRONÔMICA E FLORESTAL}

\section{THE LEARNING POTENTIAL OF GAMES IN TEACHING AGRICULTURAL AND FOREST ENGINEERING \\ EL POTENCIAL FORMATIVO DEL JUEGO EN LA ENSEÑANZA DE INGENIERÍA AGRONÓMICA Y FORESTAL}

Rodrigo Iwata Fujiwara* Rosebelly Nunes Marques**

\section{Resumo}

Este trabalho apresenta e discute a experiência de elaboração de um jogo didático envolvendo conteúdo da área de Ciências Florestais. Além disso, aborda o uso de recursos didáticos e como cada tipo de material pode estimular o processo de ensino-aprendizagem do aluno. O jogo foi aplicado com graduandos dos cursos de Engenharia Agronômica e Engenharia Florestal. A análise dos dados coletados por meio de questionários revelou que os estudantes consideram os recursos didáticos ferramentas importantes para o processo de ensino e que a aplicação do jogo despertou o interesse pelo tema.

Palavra-chave: Recurso didático. Floresta. Jogos didáticos. Ensino.

\section{Abstract}

This paper presents and discusses the experience of creating an educational game involving content from the area of Forest Sciences. Moreover, discusses the use of educational resources and how each type of material can stimulate the teaching-learning process for students. The game was applied to undergraduate students in the Agricultural Engineering and Forest Engineering programs. The analysis of the data collected using questionnaires revealed that the students considered the educational resource tools to be important for the teaching process and that the application of the game sparked an interest in the topic.

Keywords: Educational resource. Forest. Educational games. Teaching. 


\section{Resumen}

Este trabajo presenta y debate la experiencia de elaboración de un juego didáctico que comprende contenido del área de las Ciencias Forestales. Además, discute sobre el uso de recursos didácticos y cómo cada tipo de material puede estimular el proceso de enseñanza-aprendizaje del alumno. El juego se aplicó con graduandos de los cursos de Ingeniería Agronómica e Ingeniería Forestal. El análisis de los datos recogidos por medio de cuestionarios reveló que los estudiantes consideran los recursos didácticos herramientas importantes para el proceso de enseñanza y que la aplicación del juego despertó el interés por el tema.

Palabras clave: Recurso didáctico. Ciencias Forestales. Juegos didácticos. Enseñanza.

\section{Introdução}

A abordagem convencional do tema floresta, nas escolas, consiste na realização de aulas teóricas, que muitas vezes não atraem o interesse do aluno, sendo necessária uma estratégia diferente. A diversificação das estratégias de ensino auxilia a aprendizagem dos alunos, possibilitando que todos possam, de alguma forma, compreender e refletir sobre os assuntos vistos em sala de aula. Nesse contexto, os recursos didáticos possibilitam que isso ocorra aliando a teoria à prática. Os recursos de ensino possibilitam ao aluno conhecer fatos, realizar experiências e vivenciar situações que não seriam possíveis no seu dia a dia. O material didático visa simular a realidade da maneira mais fiel possível, facilitando o processo de ensino e aprendizagem.

O presente trabalho visa a elaboração, aplicação e avaliação de um jogo didático, envolvendo conteúdos abordados em disciplinas do curso de Engenharia Florestal, visto que existem poucos materiais didáticos nessa área de conhecimento e que possibilitem a participação efetiva dos alunos. Além disso, discute aspectos fundamentais de um jogo didático e as diversas etapas envolvidas em sua criação, como a escolha do tema, fase de testes, construção do jogo e aplicação do jogo finalizado. Como o jogo engloba, de maneira geral, o conteúdo de diversas disciplinas, optou-se por criar um jogo de construção, em que o jogador desconhece o tema e, no processo de jogar, é introduzido aos conceitos desejados.

\section{Recursos didáticos}

Recursos didáticos são conjuntos de materiais e equipamentos presentes no ambiente educacional e que têm como função facilitar o aprendizado e despertar o interesse dos alunos pelo conteúdo. Os materiais, em sua maioria,

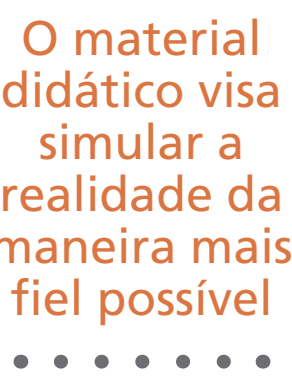


apresentam caráter audiovisual, ou seja, visam estimular a percepção visual e auditiva do aluno. De acordo com Karling (1991), a possibilidade de ver, manipular e realizar as atividades com o recurso facilita a compreensão, tornando a experiência mais concreta e significativa. Existem diversos materiais pertencentes a esse grupo, como mapas, kits pedagógicos, jogos didáticos, maquetes, vídeos, conjunto de imagens, softwares e outros.

A inclusão do recurso didático, muitas vezes, serve para alterar a dinâmica da aula e a relação aluno-professor, deixando o modelo tradicional, em que os alunos apenas ouvem e anotam o que o professor está falando. A utilização do recurso didático, por si só, não garante o ensino e muito menos sua qualidade, ele serve como instrumento de auxílio para o educador (BARBOSA; MOURA, 2013; FREITAS, 2007; MELO; KATO, 2016). O educador deve realizar um planejamento para utilizar o recurso, não somente colocar o material na frente do aluno e pedir a ele para usá-lo. O planejamento deve criar um ambiente favorável para o ensino-aprendizado dos alunos (PIMENTA; CARVALHO, 2008). Melo e Kato (2016) afirmam que planejar é uma atividade complexa, que exige elaboração, execução e avaliação da prática pedagógica. A utilização ou não de um recurso deve seguir alguns critérios, como avaliar se o material é adequado para o conteúdo a ser ministrado, é acessível (local para compra de material e custo), se os alunos têm interesse pelo material em si, sentem-se atraídos etc.

Com a presença de diversos tipos de recursos, cada um com características e maneiras de interação distintas, fez-se necessária uma divisão/classificação entre eles. Dale (1946) criou uma ferramenta para explicar a inter-relação entre os diferentes métodos de ensino e classificar sua eficiência na transmissão do conhecimento. Os diferentes métodos de ensino foram dispostos em um cone, denominado Cone da Experiência (Figura 1). No topo do cone, encontram-se as classes em que o aluno é mais passivo, interage menos com o conteúdo e a retenção de informações tende a ser menos eficiente. Uma das classes dessa área são os Símbolos Verbais, os quais são representados por palavras, fórmulas, conceitos, ideias etc. A característica principal dessa classe é a abstração, ou seja, o símbolo ou a palavra em si não tem semelhança nenhuma com o que está denominando, por exemplo, a palavra árvore não remete à aparência de uma árvore ou passa a sensação de estar perto de uma. Já na base do cone encontram-se as classes em que o aluno tem maior participação, interage diretamente com o conteúdo e o processo de aprendizado é mais eficiente. A classe Experiência Direta denota a realização da atividade em primeira mão visando ao aprendizado, ou seja, por exemplo, realizar as atividades de um inventário florestal (instalação de parcelas, mensuração das árvores etc.) para aprender o que é um inventário. Para Barbosa e Moura (2013), a educação de forma mais ativa se dá por meio da ação do próprio aluno, quando ele ouve, fala, pergunta, discute, faz e ensina. Vale lembrar que as classes deste cone não são rígidas, muitas vezes elas podem 
se misturar ou até mesmo fundir. Os materiais também não estão limitados a uma única classe, podem estar situados em duas ou mais classes.

\section{Figura 1 - Cone da Experiência}

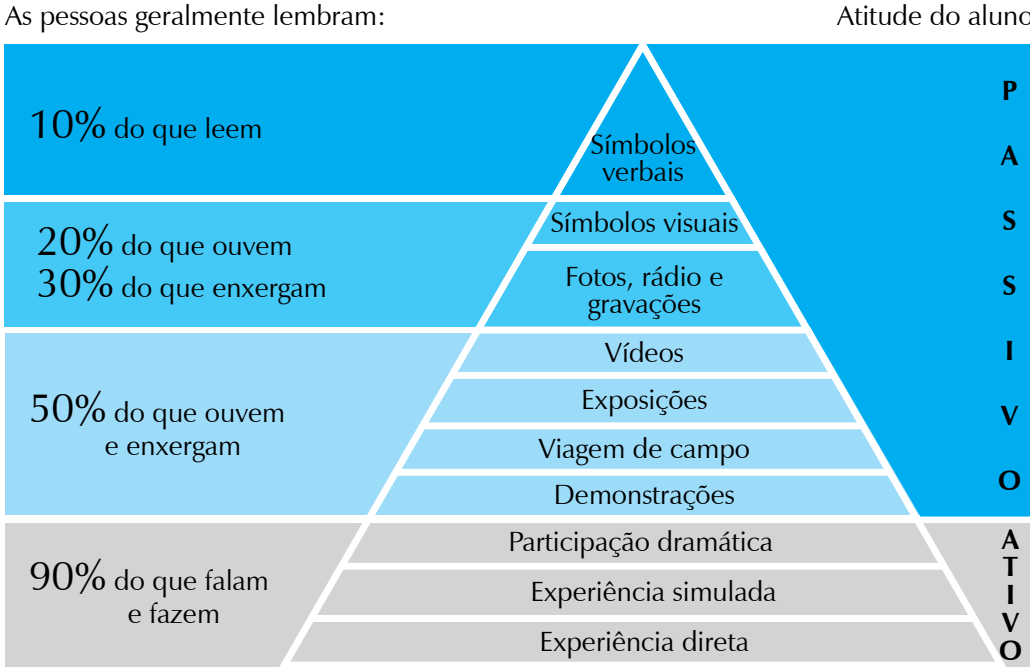

Fonte: Adaptado de Dale (1946).

Não é sensato utilizar apenas os métodos do topo ou somente os da base, é necessário mesclar as diferentes classes do cone. Nem sempre será possível realizar a atividade propriamente dita (Experiência Direta); portanto, o educador deve utilizar diferentes artifícios para favorecer o aprendizado. A estratégia de diversificar também é favorável, pois cada aluno aprende de maneira diferente e tem interesses distintos (PIMENTA; CARVALHO, 2008). De acordo com Ottonelli, Viero e Rocha (2015), o professor deve conhecer a realidade de seus alunos com o objetivo de escolher as metodologias mais apropriadas para o processo de ensino-aprendizagem.

No caso dos jogos ou recursos didáticos, estes são classificados como Experiência Simulada. O foco desta classe é simular o que está sendo ensinado. O modelo ou a simulação difere do que está sendo representado, tanto em tamanho com em complexidade, e tal simplificação ajuda o aluno a compreender o conteúdo a ser trabalhado (DALE, 1946). Como se encontra próximo à base da pirâmide, o nível de assimilação e interação do aluno com o conteúdo tende a ser maior.

\section{Jogos didáticos}

Um jogo é finito, ou seja, decorrido um período de tempo, ele "acaba", mas não significa que não possa ser jogado novamente ou repetido imediatamente. As influências de um jogo não estão restritas ao período de tempo que 
$\bullet \bullet \bullet \bullet \bullet$

O USO

dos jogos didáticos

na área de Agrárias tem apresentado resultados positivos é jogado, mas são carregadas pelo jogador após seu término. O jogo possui regras, ou seja, as leis absolutas que regem aquela realidade, e o descumprimento destas implica a retirada/expulsão do infrator (HUIZINGA, 2007; KISHIMOTO, 2006). Para Caillois (1986), a palavra jogo não nomeia somente a atividade, mas todos os seus componentes e peças, todo o conjunto. $\mathrm{O}$ jogo deve ocorrer em uma área específica/delimitada formada de maneira material ou imaginária. Esse "mundo" pode aparecer como uma quadra de tênis, fragmento da rua, área da amarelinha ou ambiente imaginário. $\mathrm{Na}$ questão imaginária, podem-se citar as crianças, que utilizam a imaginação para criar diversas situações e personagens, mas têm total consciência de que estão apenas brincando e jogando. Além desse espaço, o jogo também pode apresentar diferentes componentes, por exemplo, um jogo de baralho é formado pelo seu conjunto de cartas, enquanto que o xadrez é composto por suas diversas peças. A ausência de um único elemento pode tornar a experiência incompleta e descaracterizá-lo, lembrando que alguns jogos não necessitam de instrumentos nem de acessórios.

Os jogos didáticos aparecem como ferramenta de auxílio para a cognição (formação de conceitos, imaginação e vocabulário), socialização (interação em grupo, construção de personalidade), afeição (criação de um vínculo com o conteúdo estudado), motivação (interesse na participação das atividades propostas) e criatividade (MIRANDA, 2001). Kishimoto (2006) defende que o jogo é uma ferramenta de resolução de problemas, visando aproximar os usuários de situações reais e transmitir conhecimentos presentes no jogo. O jogo é uma ferramenta de auxílio ao professor e não deve ser utilizado para substituí-lo. O professor deve ter um planejamento para utilizá-lo, visando associar conhecimentos previamente obtidos, bem como a construção de novos. Segundo Caillois (1986), o jogo não ensina/segue receitas, mas sim promove o desenvolvimento de aptidões; e, quanto mais distantes da realidade forem as situações provocadas, melhor será seu desenvolvimento. Duflo (1999) alerta que tal atividade necessita de um certo nível de cuidado, pois, ao ser realizada em excesso, pode tornar-se exaustiva, portanto, é necessário o estabelecimento de limites para evitar tais problemas.

O uso dos jogos didáticos na área de Agrárias tem apresentado resultados positivos, como citado por Chagas, Simões e Marques (2014) e Pereira Junior, Marques e Chagas (2014). Os estudantes consideraram os recursos como ferramentas eficazes para o aprendizado, além de estimularem seu interesse sobre o tema abordado e reforçarem os conhecimentos pré-adquiridos. Tais resultados estão diretamente relacionados à qualidade de aprendizado dos alunos, como abordado no "Cone da Experiência" (DALE, 1946). 


\section{Conteúdo curricular - Ciências Florestais}

Existem diversas definições de floresta, as mais simples normalmente são encontradas em dicionários e expressam de maneira bem superficial o que é uma floresta. "Vegetação cerrada constituída de árvores de grande porte, cobrindo grande extensão de terreno; mata" (MICHAELIS, 1998, p. 969).

As definições mais simples acabam identificando uma floresta apenas como um conjunto de árvores e refletem como as pessoas que têm pouca interação com tal ambiente o enxergam. Conforme o nível de aprofundamento no tema vai aumentando, podem-se encontrar definições mais complexas, que definem a floresta de acordo com suas características estruturais, além de avaliar sua condição atual e futura.

Floresta é uma área de terra de no mínimo 0,05-1,0 ha com a cobertura das copas cobrindo (ou densidade equivalente) mais de $10-30 \%$, com árvores com o potencial de atingir a altura mínima de 2-5 metros na maturidade in situ. Uma floresta pode consistir tanto de formações florestais fechadas, onde árvores de vários estratos cobrem uma alta proporção do solo, ou de florestas abertas. Povoamentos naturais jovens e todas as plantações que ainda atingirão densidade de 10$30 \%$ ou uma altura entre 2 e 5 metros são incluídos como floresta, assim como áreas que normalmente fazem parte da área florestal e que estão temporariamente desflorestadas como resultado da intervenção humana, como a colheita ou causas naturais, mas cuja reversão da floresta é esperada (UNITED NATIONS FRAMEWORK CONVENTION ON CLIMATE CHANGE, 2010, p. 122).

As definições, de forma geral, acabam frisando apenas a árvore como parte de uma floresta. Contudo ao analisar mais detalhadamente, nota-se que ela é composta por uma gama muito maior de plantas, como arbustos, gramíneas, epífitas, bambus, lianas e outras mais (LIMA et al., 2012). Cada um dos organismos citados apresenta características diferentes tanto individualmente como dentro de suas populações (indivíduos da mesma espécie). As diferenças podem ser observadas em diversos aspectos, como na quantidade de indivíduos de cada população, que variam de poucos até centenas de indivíduos, no tamanho, desde uma gramínea de poucos centímetros até uma árvore com dezenas de metros; ou na distribuição espacial dos indivíduos da mesma população, em alguns casos eles podem estar agrupados ou separados a longas distâncias (BAZARIAN; SILVA, 2015).

Como citado na segunda definição, as áreas onde as florestas se encontram e a própria floresta podem sofrer transformações. Quando um local alcança o estado de floresta, ele continua a se transformar. A floresta não é estática, conforme a passagem do tempo, a comunidade vegetal de determinado local começa a se transformar em outra, por meio do aparecimento/chegada 


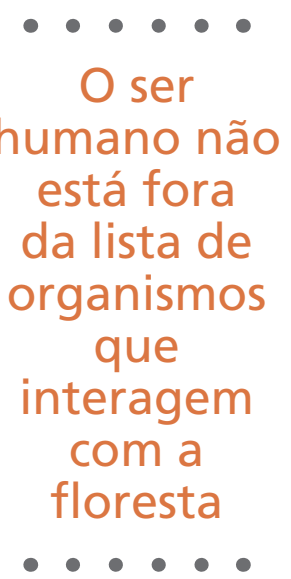

de outras espécies, das flutuações do número de indivíduos originais e até mesmo do desaparecimento de algumas espécies. Esse processo ecológico de transformação, recuperação ou formação natural de uma vegetação é denominado sucessão florestal (DURIGAN; TABARELLI; CHAZDON, 2015).

Os animais também fazem parte da floresta e realizam diversas atividades que possibilitam seu desenvolvimento. A diversidade de animais dentro de uma floresta é enorme, pode-se citar desde um pequeno inseto, como uma abelha, até um grande mamífero, como a anta (Tapirus terrestris). Os insetos como abelhas, mariposas e borboletas têm papel fundamental para a reprodução de muitas espécies de planta, atuando como polinizadores (GOULSON, 1999), enquanto os mamíferos como a anta realizam a dispersão de sementes (HOWE; SMALLWOOD, 1982).

O ser humano não está fora da lista de organismos que interagem com a floresta, já que este tem uma forte ligação com a mesma. A relação homem/ floresta ocorre por meio da utilização de seus recursos, podendo ser realizada de forma predatória ou de forma mais sustentável. No primeiro caso, pode-se citar a atividade de desmatamento (KAIMOWITZ; ANGELSEN, (1998) e, no segundo, atividades que utilizam metodologias mais sustentáveis, ou seja, retirar os recursos florestais, como madeira, frutos, folhas, resinas, óleos e gomas em quantidades adequadas, mantendo a floresta em pé (MACHADO, 2008).

\section{O jogo "Um dia na floresta"}

O foco principal desse jogo didático foi simular os processos naturais e as interferências antrópicas que ocorrem na floresta, por meio do uso de cartas e compra de peças com moedas. As peças de planta do jogo (Figura 2) representam as diferentes etapas de desenvolvimento de uma árvore, desde a fase de plântula (fase juvenil) até a sua frutificação. Estas, semelhantes a dominós, podem ser derrubadas e empurrar outras, de forma semelhante ao que ocorre naturalmente nas florestas durante a formação de clareiras. Neste jogo as cartas representam os processos naturais e as interferências antrópicas que ocorrem na floresta, como as cartas de desmatamento ilegal (retirada de uma peça do oponente) e banco de plântulas (adição de peças em seu tabuleiro). Além dos componentes, podem-se citar as peças abelha e pássaro, que são responsáveis pelas mecânicas de polinização e dispersão de sementes, respectivamente. $\mathrm{O}$ jogo acaba quando um dos tabuleiros estiver completamente preenchido pelas peças de planta, e o vencedor é aquele que obtiver a maior somatória de pontos entre suas peças.

Os componentes do jogo foram produzidos utilizando-se diferentes métodos e materiais. A matéria-prima para a confecção das peças de planta foi a 
madeira de teca (Tectona grandis) fornecida pelo Laboratório de Movelaria e Resíduos Florestais da Esalq - USP, coordenado pela Profa Adriana Maria Nolasco. O responsável técnico do laboratório, Sidney Antonio Theodoro, realizou o esquadrejamento e lixamento das peças.

Figura 2 - Peças de planta

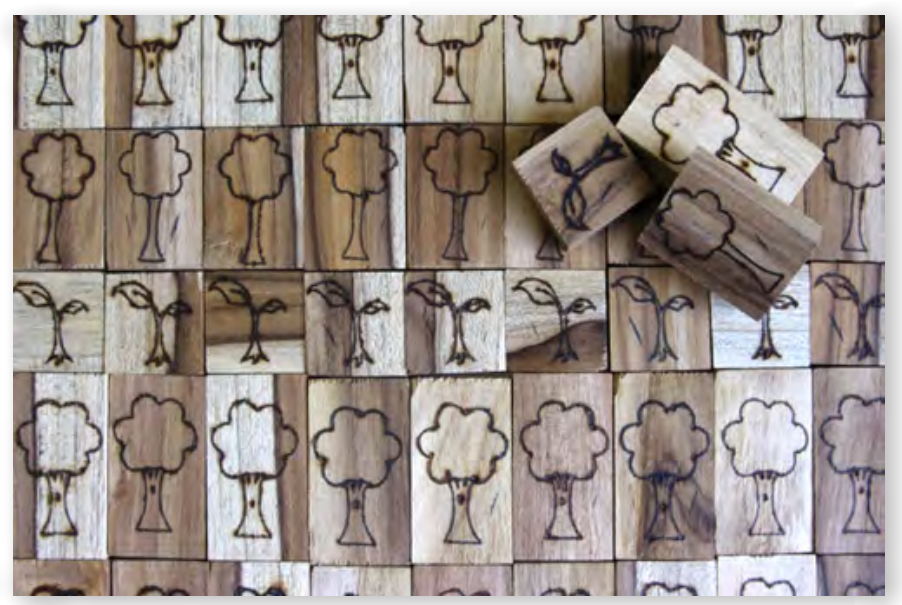

Fonte: Elaborado pelos autores.

As cartas e o tabuleiro (Figura 3) foram impressos em papel sulfite nos tamanhos A4 e A3, respectivamente. As imagens utilizadas foram retiradas do banco de fotos Pixabay (https://pixabay.com/), um site de armazenamento e disposição de fotos gratuitas.

Figura 3 - Cartas e tabuleiro

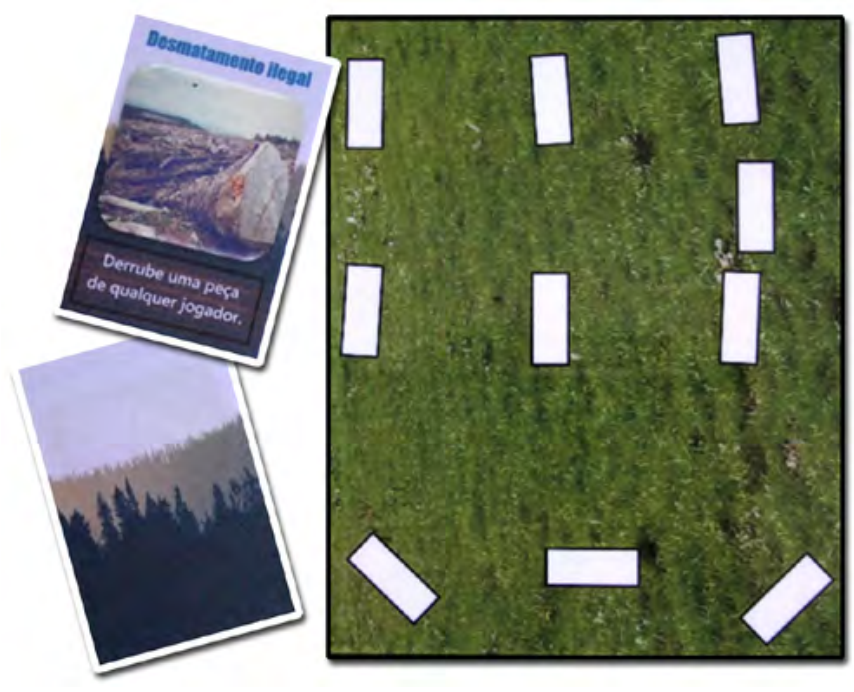

Fonte: Elaborado pelos autores. 
As demais peças do jogo foram obtidas em lojas de baixo custo (bijuterias), sofrendo as devidas modificações (Figura 4).

\section{Figura 4 - Componentes do jogo obtidos em lojas de baixo custo}

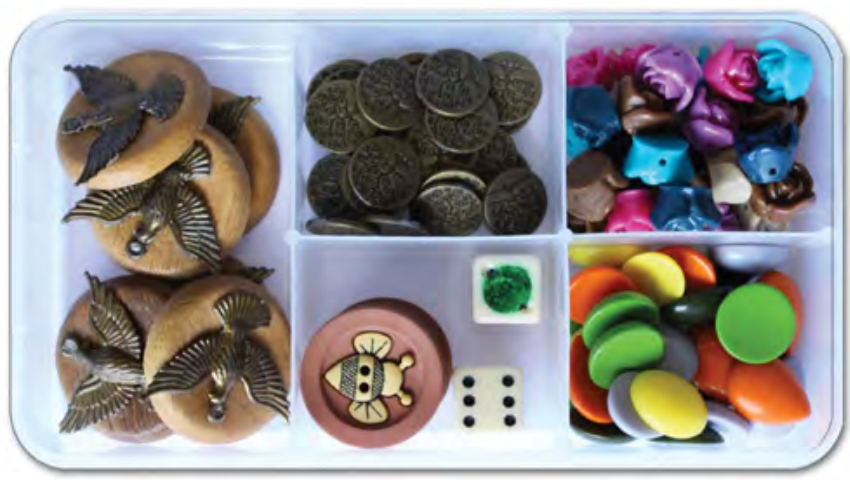

Fonte: Elaborado pelos autores.

\section{Testes para aprimoramento}

Esta fase de testes é necessária para se compreender a perspectiva dos participantes com relação ao recurso e verificar se as instruções presentes no manual estão transmitindo, de maneira ideal, a proposta e as regras do jogo. Segundo Ludke e André (2012), cada pessoa possui uma visão diferente para diferentes objetos e situações, em razão do seu processo de formação educacional e de suas experiências de vida. Tal fator permite que cada indivíduo foque determinado fator e preste pouca atenção em outros.

O método de análise do jogo foi a observação direta dos jogadores por meio de dois testes: Mecânica e Manual. O primeiro teste analisou se as mecânicas não atrapalhavam o fluxo do jogo, enquanto que o segundo analisou se as regras estavam sendo interpretadas da maneira correta. Os testes possibilitaram que as regras e as mecânicas fossem validadas, bem como sua posterior modificação ou adaptação.

Os testes foram realizados com grupos de três a quatro pessoas, e no total 32 pessoas participaram da fase de testes, incluindo indivíduos que não atuam na área de Agrárias. 


\section{Instrumentos para coleta de dados}

Optou-se por utilizar questionários semiabertos, pré e pós-jogo, como ferramentas de coleta de dados escritos, além das observações do próprio pesquisador. Para os aspectos éticos, elaborou-se um Termo de Consentimento Livre e Esclarecido (TCLE), em que os participantes concordavam em participar da pesquisa de forma voluntária e resguardando o sigilo de sua identidade pessoal. Os participantes consentiam: 1. Participação na aplicação do jogo, em sala de aula; 2. Participar da discussão coletiva acerca das atividades desenvolvidas; e 3. Responder questionários individualmente.

O questionário é um relato do participante sobre sua experiência, no qual é possível observar as alterações de comportamento, percepção e conhecimento sobre determinado tema ao longo do tempo (LANKSHEAR; KNOBEL, 2008). O questionário pré-jogo obteve a opinião dos participantes sobre recursos didáticos de maneira geral, quais recursos tinham utilizado ao longo de sua formação, domínio de alguns conceitos da área florestal e com que frequência praticavam jogos. O questionário pós-jogo buscava a opinião do participante sobre o jogo e sua experiência ao utilizá-lo.

Os questionários foram aplicados em 13 alunos da disciplina LES0342 - Instrumentação para o Ensino de Ciências Agrárias, durante duas oficinas sobre jogos didáticos.

\section{Análise dos dados}

Os dados coletados foram digitalizados, e em seguida cada conjunto de respostas foi analisado, começando pelo questionário pré-jogo seguido pelo pós-jogo. A primeira pergunta do questionário pré-jogo foi "Ao longo do ensino médio e da graduação, você utilizou recursos didáticos (maquetes, vídeos, softwares, jogos didáticos etc.)? Caso sim, cite a disciplina e especifique o material", e os alunos citaram a utilização de diversos recursos didáticos durante o ensino médio e ao longo da graduação. Os materiais estavam presentes em diversas disciplinas e, em alguns casos, mais de um recurso era utilizado por conteúdo. Os materiais variaram de softwares e vídeos (mídias digitais) até recursos montados pelos próprios alunos, como maquetes, herbários e experimentos.

Na questão 2, "Avalie a utilização dos recursos citados anteriormente para a compreensão do conteúdo?", mais de 90\% dos alunos relataram que o uso dos materiais citados teve efeito positivo para a compreensão do conteúdo abordado (Gráfico 1). Tal resultado demonstra a potencialidade dos recursos didáticos para o ensino, se utilizados corretamente. 


\section{Gráfico 1 - Avaliação do uso dos recursos}

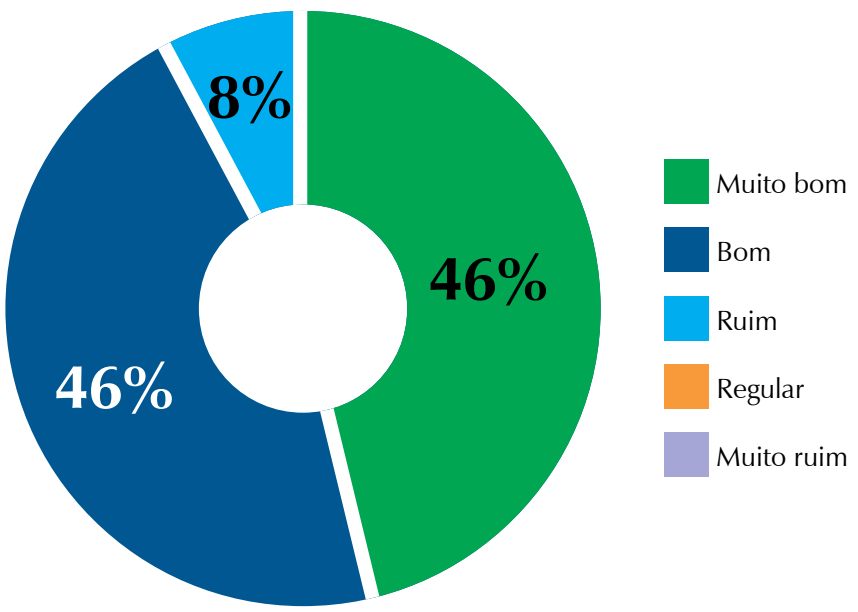

Fonte: Elaborado pelos autores.

Já na questão 3, "Qual sua opinião sobre a utilização de recursos didáticos no ensino de conteúdos?", os alunos expuseram suas opiniões sobre recursos didáticos e frisaram diversos aspectos positivos ao utilizá-los, como: auxilia a fixação do conteúdo, facilita a compreensão e desperta o interesse pelo tema. O relato do aluno A comenta sobre alguns benefícios: "Os recursos didáticos auxiliam o ensino, tornando-o mais leve e inteligível. Também predem a atenção do aluno e, em alguns casos, o estimulam a estudar e procurar mais sobre o assunto".

Outro fator, destacado pelo aluno B, é a alteração na dinâmica da aula:

\section{É de suma importância, logo que o fator diversão e entrete- nimento acabam trazendo mais praticidade e menos pressão ao aluno, fazendo com que muitas das vezes o aluno aprenda assimilando as ideias de forma mais produtiva e menos expo- sitiva.}

De forma geral, o uso de recursos didáticos é bem-visto, mas deve-se tomar cuidado ao utilizá-los, como citado pelo aluno C, que indica uma limitação para o uso de materiais desse tipo: "Válido, porém tem que ser bem elaborado e aplicado para não virar bagunça e não ter finalidade didática alguma".

Vale lembrar que o recurso em si não garante um bom aprendizado dos alunos, mas o planejamento adequado do professor, sim. O fato de os alunos terem opiniões favoráveis em relação a recursos didáticos e terem passado por boas experiências ao utilizá-los reforça a introdução ou o uso de novos recursos.

Na questão 4, "Assinale os itens em que você se sente confortável em discutir ou explicar o conceito", os alunos de Engenharia Florestal se sentiram 
confortáveis em discutir a maioria dos conceitos apresentados (Gráfico 2), indicando que a abordagem desses conceitos está presente e é pertinente ao curso de Engenharia Florestal. O jogo poderia ser aplicado em disciplinas introdutórias do curso de Engenharia Florestal, pois possibilitaria ao ingressante do curso conhecer, superficialmente, alguns aspectos da floresta que serão discutidos futuramente. Os alunos de Engenharia Agronômica responderam que não se sentem confortáveis em discutir alguns conceitos importantes da área florestal, como sucessão florestal, restauração florestal e manejo florestal. Como o jogo integra tais conhecimentos, ele poderia ser aplicado nas disciplinas que associam o conteúdo florestal com a área de agrárias, visando introduzir esses temas e possivelmente despertar o interesse por eles.

\section{Gráfico 2 - Porcentagem de alunos que se sentem confortáveis em discutir os diversos conceitos}

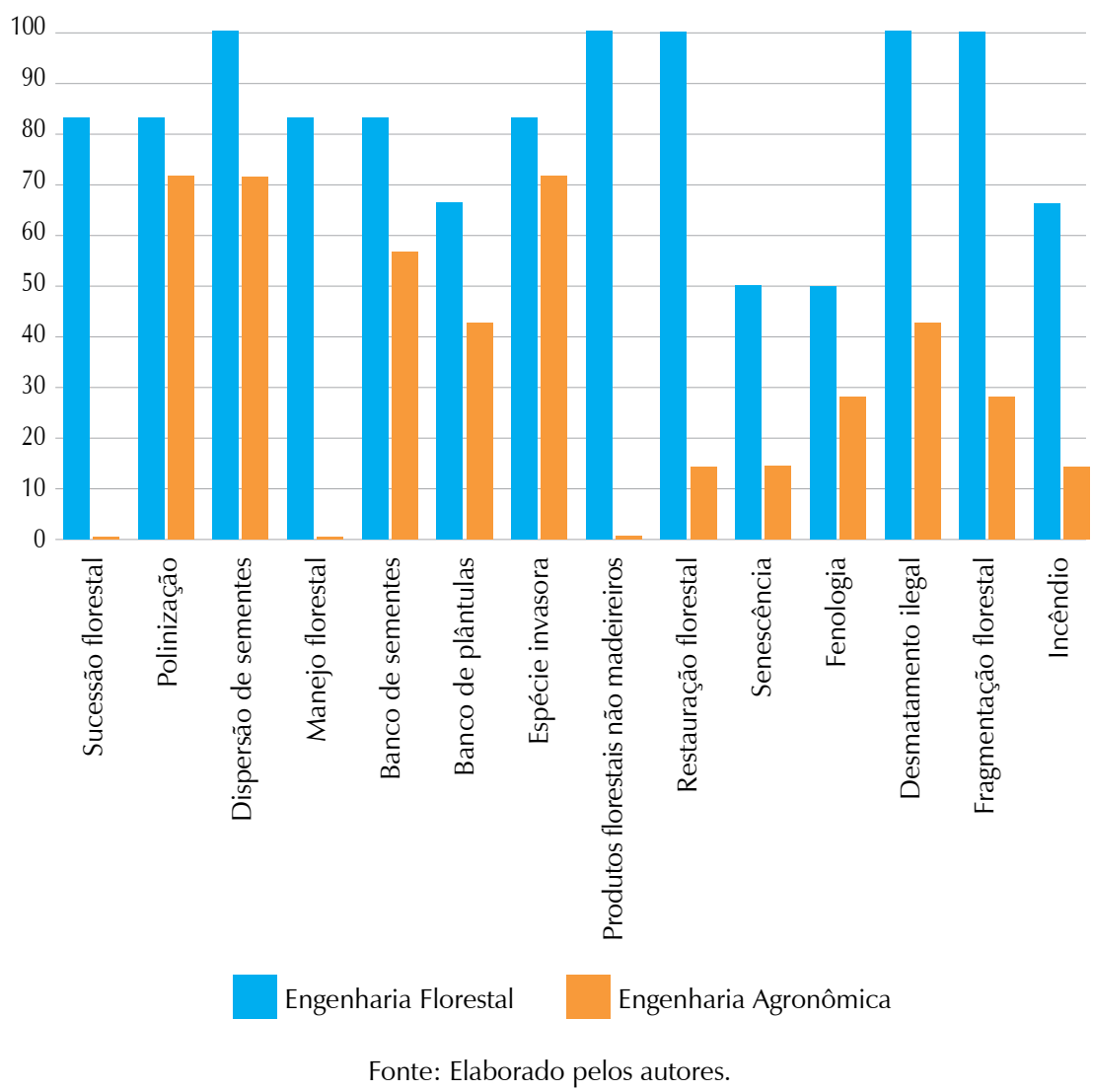

Na questão 5, "Com qual frequência você joga videogame, baralho ou jogos de tabuleiro com amigos e familiares?", mais da metade dos estudantes não tem o hábito de jogar qualquer tipo de jogo, como pode ser observado no Gráfico 3. Tal informação reforça a ideia do jogo didático como atividade nova, ou seja, uma mudança na dinâmica da aula. 


\section{Gráfico 3 - Frequência com que os participantes jogam}

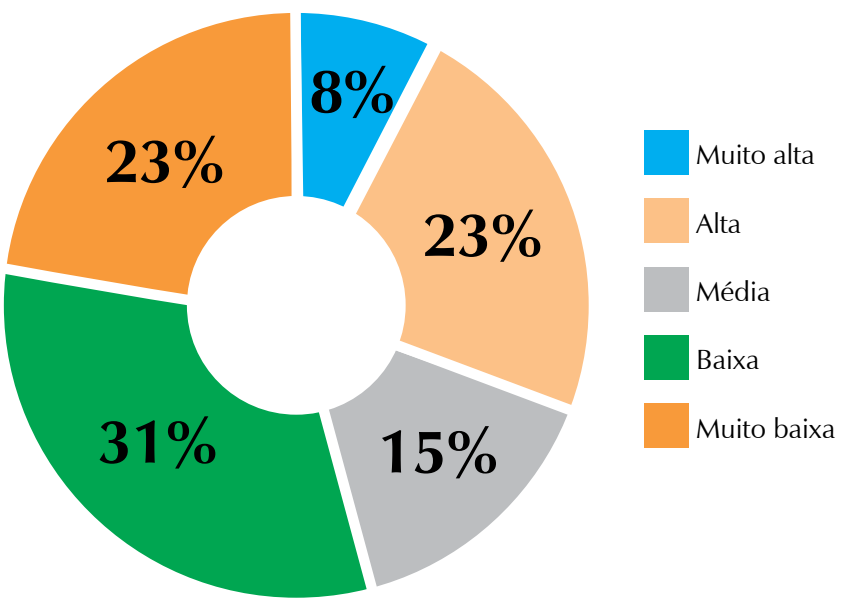

Fonte: Elaborado pelos autores.

As respostas da questão 2 do questionário pós-jogo, "Qual seu nível de interesse/atenção ao utilizar o jogo Um dia na floresta?", indicaram que a atenção dos alunos ao utilizar o jogo foi alta, conforme representado no Gráfico 4. Como descrito anteriormente, os participantes não têm o hábito de jogar jogos, mas, apesar de ser uma atividade a qual estão pouco acostumados, o joga acaba atraindo sua atenção. O fator competição também pode ser responsável por esses resultados; como os participantes têm que observar seus oponentes e acompanhar o que eles estão fazendo, estes acabam focando mais a atividade.

\section{Gráfico 4 - Nível de atenção dos participantes ao jogar}

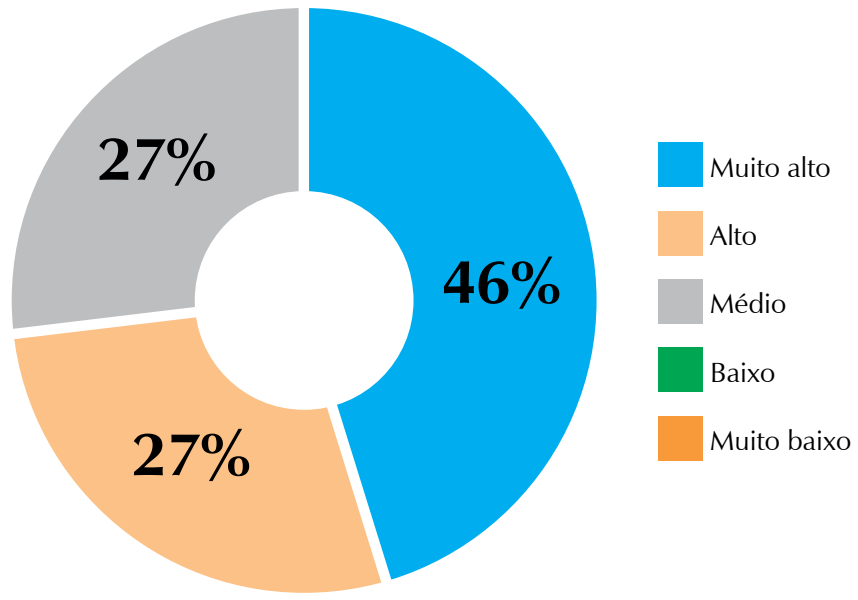

Fonte: Elaborado pelos autores. 
Na questão 3, "O uso do jogo didático Um dia na floresta despertou o interesse para o tema? Por quê?", os alunos relataram que o jogo didático contemplou as características desejadas, pois, de acordo com o comentário do aluno D, garantiu uma alteração do processo de ensino e despertou o interesse do estudante pela área florestal: "Sim, apesar de já ter interesse no tema, o jogo mostrou que é possível ensiná-lo de uma forma mais dinâmica".

A simulação do ambiente florestal também foi bem-sucedida, como pode ser visto na resposta do aluno E: "Sim, porque o jogo conseguiu unir diversos temas/conteúdos, e vê-los em prática em um jogo é empolgante". O aluno F também cita esse fato: "Sim, pois deixou clara a conexão que existe entre componentes de um sistema florestal e como afetam-se".

\section{Considerações finais}

A alteração das metodologias convencionais de ensino e a utilização de diferentes ferramentas pedagógicas alteram a dinâmica da aula, aumentando o interesse dos alunos pelo tema e facilitando o aprendizado. Cada aluno possui sua própria maneira de aprender, e os diferentes recursos didáticos possibilitam interações diferentes com o conteúdo. A utilização de recursos didáticos necessita de um bom planejamento e não deve ser vista como ferramenta de sucesso garantido para o aprendizado. No caso dos jogos didáticos, esse tipo de ferramenta traz a possibilidade de associar conteúdo com a ludicidade, mas precisa-se de atenção para não se tornar apenas um brinquedo. Frequentemente, a metodologia e/ou o material utilizado deixam as informações muito abstratas ou difíceis de compreender, sendo necessário efetuar testes para validar as mecânicas. A fase de testes é essencial para verificar se o jogo está funcionando de acordo com o esperado e possibilita que o desenvolvedor escute opiniões e sugestões para aprimorar seu jogo.

Como a floresta encontra-se distante do ambiente urbano, a utilização de recursos didáticos é vital para aproximar os dois locais. Essas ferramentas permitem que os alunos, por meio de atividades práticas, visualizem o ambiente florestal e/ou tomem conhecimento sobre os processos naturais de uma floresta, bem como sua relação com o ser humano.

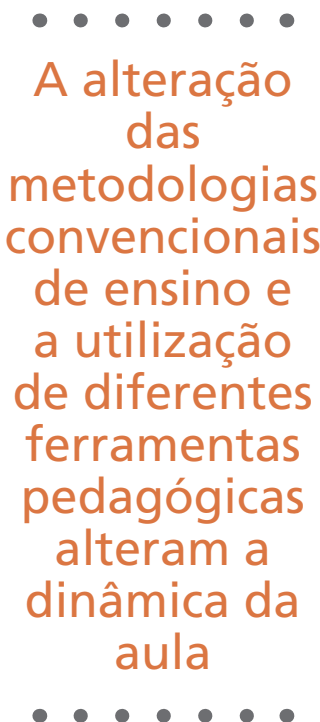




\section{Referências}

BARBOSA, E. F.; MOURA, D. G. Metodologias ativas de aprendizagem na educação profissional e tecnológica. Boletim Técnico do Senac, Rio de Janeiro, v. 39, n. 2, p. 48-67, maio/ago. 2013. Disponível em: <http://www.senac.br/media/42471/ os_boletim_web_4.pdf>.Acesso em: 19 out. 2016.

BAZARIAN, S.; SILVA, W. R. Bases conceituais para a restauração florestal: processos ecológicos reguladores de comunidades vegetais. In: BRANCALION, P. H. S.; GANDOLFI, S.; RODRIGUES, R. R. Restauração florestal. São Paulo: Oficina de Textos, 2015. cap. 4, p. 103-134.

CAILLOIS, R. Los juegos y los hombres: la máscara y él vétigo. México: Fondo de Cultura Económica, 1986.

CHAGAS, I. H.; SIMÕES, L. H. P.; MARQUES, R. N. Conhecendo o "novo código florestal" por meio de um jogo didático. In: JORNADA DAS LICENCIATURAS DA USP, São Carlos, 2014. A Universidade pública na formação de professores: ensino, pesquisa e extensão: anais. São Carlos: USP, 2014.

DALE, E. Audio-visual methods in teaching. New York: Dryden Press, 1946.

DUFLO, C. 0 jogo: de Pascal a Schiller. Porto Alegre: Artes Médicas Sul, 1999.

DURIGAN, G.; TABARELLI, M.; CHAZDON, R. L. Bases conceituais para a restauração florestal: processos ecológicos reguladores e um modelo de fases. In: BRANCALION, P. H. S.; GANDOLFI, S.; RODRIGUES, R. R. Restauração florestal. São Paulo: Oficina de Textos, 2015. cap. 5, p. 135-160.

FREITAS, O. Equipamentos e materiais didáticos. Brasília, DF: Universidade de Brasília, 2007.

GOULSON, D. Foraging strategies of insects for gathering nectar and pollen, and implications for plant ecology and evolution. Southampton: University of Southampton, 1999.

HOWE, H. F.; SMALLWOOD, J. Ecology of seed dispersal. Annual Review of Ecology and Systematics, v. 13, p. 201-228, Nov. 1982.

HUIZINGA, J. Homo ludens: o jogo como elemento da cultura. São Paulo: Perspectiva, 2007.

KAIMOWITZ, D.; ANGELSEN, A. Economic models of tropical deforestation: a review. Bogor: Ciflor, 1998.

KARLING, A. A. A didática necessária. São Paulo: Ibrasa, 1991.

KISHIMOTO, T. M. Jogo, brinquedo, brincadeira e a educação. São Paulo: Cortez, 2006.

LANKSHEAR, C.; KNOBEL, M. Pesquisa pedagógica: do projeto à implementação. Porto Alegre: Artmed, 2008.

B. Téc. Senac, Rio de Janeiro, v. 43, n. 3, p. 86-103, set./dez. 2017. 
LIMA, R, A, F. et al. Composição, diversidade e distribuição geográfica de plantas vasculares de uma floresta ombrófila densa atlântica do sudeste do Brasil. Campinas: Biota Neotrop, 2012.

LUDKE, M.; ANDRÉ, M. E. D. A. Pesquisa em educação: abordagens qualitativas. São Paulo: E.P.U., 2012.

MACHADO, F. S. Manejo de produtos florestais não madeireiros: um manual com sugestões para o manejo participativo em comunidades da Amazônia. Rio Branco: Pesacre: Ciflor, 2008.

MELO, G. F.; KATO, M. N. C. Docência na educação superior: em foco as ciências agrárias. Boletim Técnico do Senac, Rio de Janeiro, v. 42, n. 1, p. 70-89, jan./abr. 2016. Disponivel em: <http://www.senac.br/media/105088/bts_42_70.pdf>. Acesso em: 19 out. 2016.

MICHAELIS: moderno dicionário da língua portuguesa. São Paulo: Melhoramentos, 1998.

MIRANDA, S. No fascínio do jogo, a alegria de aprender. Linhas Críticas, Brasília, v. 8, n. 14, p. 21-34, jan./jun. 2002.

OTTONELLI, J.; VIERO, E. F. F.; ROCHA, K. M. Estudo de caso: metodologia de ensinoaprendizagem na educação profissional. Boletim Técnico do Senac, Rio de Janeiro, v. 41, n. 3, p. 54-69, set./dez. 2015. Disponível em <http://www.senac.br/ media/97764/pag_54_bts_41_3_bx6.pdf>. Acesso em: 19 out. 2016.

PEREIRA JUNIOR, E.; MARQUES, R. N.; CHAGAS, I. H. Jogos didáticos: uma metodologia facilitadora no ensino de ciências agrárias. In: JORNADA DAS LICENCIATURAS DA USP, São Carlos, 2014. A Universidade pública na formação de professores: ensino, pesquisa e extensão: anais. São Carlos: USP, 2014.

PIMENTA, S. A.; CARVALHO, A. B. G. C. Didática e o ensino de geografia. Campina Grande: EDUEP, 2008.

UNITED NATIONS FRAMEWORK CONVENTION ON CLIMATE CHANGE. The

Marrakesh accords \& the Marrakesh declaration. Bonn, 2010. 


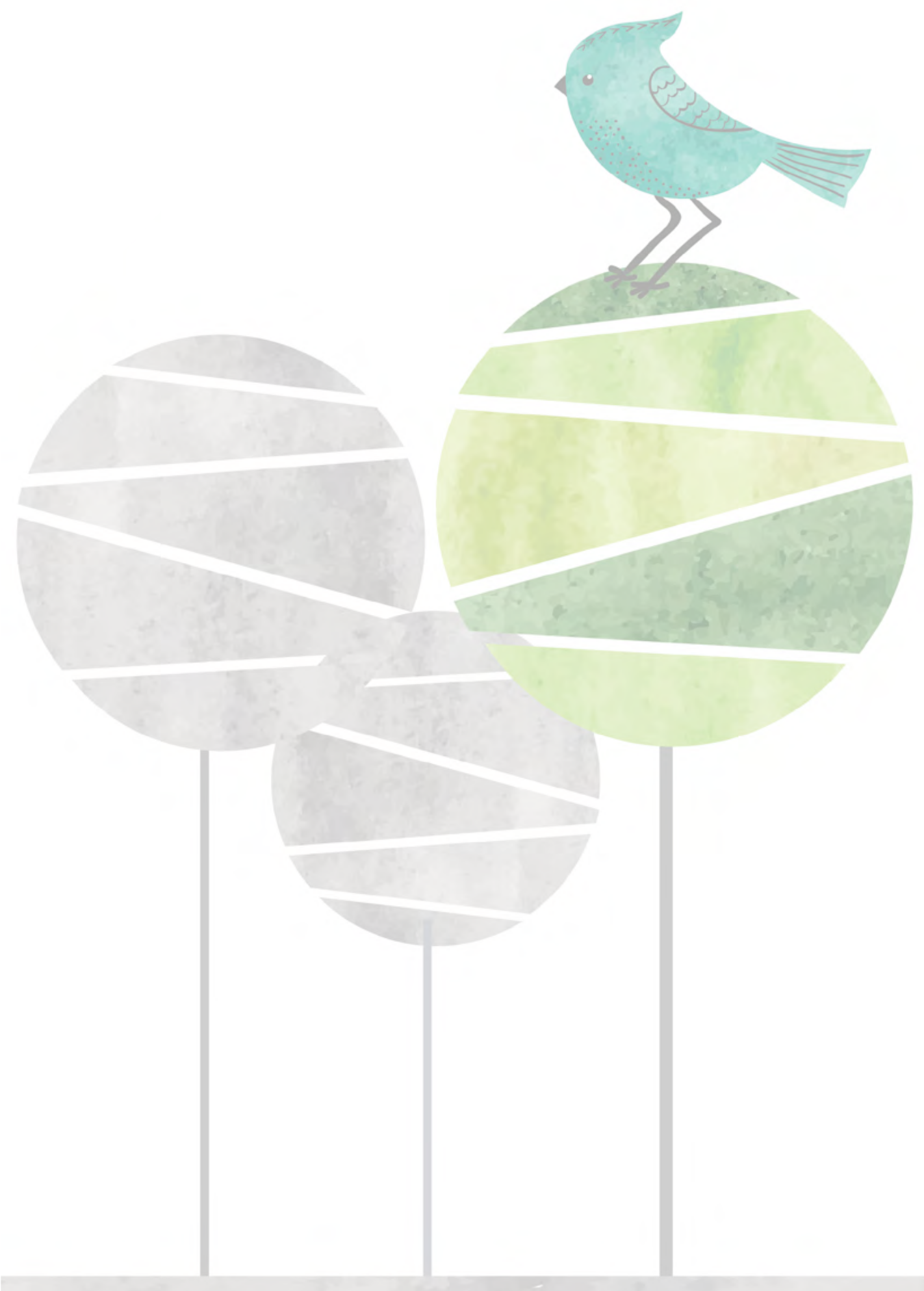

B. Téc. Senac, Rio de Janeiro, v. 43, n. 3, p. 86-103, set./dez. 2017. 